\title{
Retrospective German claims data study on initial treatment of bladder carcinoma (BCa) by transurethral bladder resection (TURB): a comparative analysis of costs using standard white light- (WL-) vs. blue light- (BL-) TURB
}

\author{
Tilman Todenhöfer ${ }^{1,2}$ (D) Moritz Maas ${ }^{1} \cdot$ Miriam Ketz $^{3} \cdot$ Nils Kossack $^{4} \cdot$ Christiane Colling $^{5} \cdot$ Bryan $_{\text {Qvick }}{ }^{5} \cdot$ \\ Arnulf Stenzl ${ }^{1}$
}

Received: 27 September 2020 / Accepted: 29 December 2020 / Published online: 10 February 2021

(c) The Author(s) 2021

\begin{abstract}
Purpose Photodynamic diagnosis using hexaminolevulinate (HAL) — guided BL-TURB may reduce the recurrence risk in non-muscle invasive BCa compared to standard WL-TURB due to more sensitive tumor detection. The impact of the initial use of WL- vs. BL-TURB on follow-up costs was evaluated in this real-world data analysis.

Methods Anonymous claims data of German statutory health insurances (GKV) from 2011 to 2016 were analyzed in a primary and adjusted study population. Selection criteria included five quarters before enrolment, one index quarter (InQ) of initial TURB and BCa diagnosis, either within two years for the primary analysis or within four years for the adjusted analysis, and a follow-up period (FU) of either eleven or three quarters, respectively.

Results In the primary analysis $(n=2331)$, cystectomy was identified as an important cost driver masking potential differences between cohorts. Therefore, patients undergoing cystectomy (InQ $+\mathrm{FU}$ ) were excluded from the adjusted study population of $n=4541$ patients (WL: 79\%; BL: 21\%). Mean total costs of BL-TURB were initially comparable to WL-TURB (WL: EUR 4534 vs. BL: EUR 4543) and tended to be lower compared to WL-TURB in the first two quarters of FU. After one year (3rd FU quarter), costs equalized. Considering total FU, mean costs of BL-TURB were significantly lower compared to WL-TURB (WL: EUR 7073 vs BL: EUR 6431; $p=0.045$ ).

Conclusion This retrospective analysis of healthcare claims data highlights the comparability of costs between BL-TURB and WL-TURB.
\end{abstract}

Keywords Urothelial cancer · Transurethral bladder resection · Hexaminolevulinate $\cdot$ Photodynamic diagnosis ·

Retrospective health service research · German claims data

\section{Introduction}

Bladder cancer $(\mathrm{BCa})$ is among the ten most common cancers worldwide, with every third new case occurring in Europe [1], and also one of the most cost-consuming cancer diseases [2]. Its incidence is higher for men than for women and increases with age [3, 4]. The most common histological

Tilman Todenhöfer and Moritz Maas contributed equally to this work.

Tilman Todenhöfer

todenhoefer@studienurologie.de

Extended author information available on the last page of the article form, accounting for approximately $70 \%$ of primary diagnosed bladder tumors, is non-muscle-invasive $\mathrm{BCa}[1,3]$.

Patients with suspected $\mathrm{BCa}$ are visually examined by white light (WL) cystoscopy as a standard diagnostic procedure $[3,5,6]$. To confirm the diagnosis and establish the tumor state, a transurethral resection of the bladder (TURB) is routinely performed, which for non-muscleinvasive tumors also constitutes the initial treatment option, generally followed by immediate intravesical instillation of chemotherapy $[3,6]$. Only 10-20\% of non-muscle-invasive tumors progress to muscle-invasive tumors, but $50-70 \%$ of non-muscle-invasive tumors will recur, highlighting the need for optimal initial detection and treatment to ensure optimal prognosis [1]. Hexaminolevulinate (HAL) was approved in 
the EU and the US for assessment of non-muscle-invasive $\mathrm{BCa}$ by photodynamic diagnosis. After instillation of HAL into the bladder, photoactive porphyrin accumulates in neoplastic cells and facilitates their detection by emitting red fluorescence during cystoscopy with blue light (BL) [7]. The detection rate of tumors is improved by BL-cystoscopy compared to WL-cystoscopy by $10-20 \%$ for non-invasive papillary carcinoma and by up to $40 \%$ for carcinoma in situ [8-11]. Furthermore, the recurrence rate is reduced [10, $12-14]$ and recurrence-free survival is prolonged [13, 15] when using BL- compared to WL-cystoscopy. The impact on progression remains unclear [16-19] and depends on the criteria used to define progression [18].

Due to the high recurrence risk of $\mathrm{BCa}$, patients require continuous monitoring. The quality of the initial TURB, however, impacts prognosis and thereby also treatment costs. Models evaluating cost-effectiveness of BL- compared to WL-TURB predict increased quality-adjusted life years and lower long-term costs for BL-TURB despite BL-TURB being more expensive than WL-TURB [20-23]. So far there is only limited information available concerning initial use of WL- or BL-TURB. Using German claims data, the objective of this study was to analyze the real-world impact on costs in case of either WL- or BL-TURB applied as initial treatment in patients with $\mathrm{BCa}$.

\section{Materials and methods}

\section{Data source}

For this retrospective analysis, routine healthcare claims data from more than 60 German statutory health insurances (GKV, Gesetzliche Krankenversicherung) were used [24]. The sample comprised more than 4.5 Million individuals, GKV-insured at least one day between 2011-01-01 and 2016-12-31 and was representative concerning age, gender and morbidity in Germany. As anonymized and pseudonymized healthcare claims data were evaluated, the study was exempt from ethical approval.

\section{Study population}

The step-by-step selection process to generate the study population is shown in Fig. 1. The total study population was adjusted for further analysis of costs as indicated.

\section{Study time periods}

The primary analysis included patients whose index quarter (InQ) comprising initial TURB and concurrent diagnosis of $\mathrm{BCa}$ fell in the selection period of two years between $\mathrm{Q} 2 / 2012$ and $\mathrm{Q} 1 / 2014$. A pre-index period without any
TURB or cystoscopy before first index TURB included five quarters, from Q1/2011 until Q1/2012. The follow-up period (FU) lasted eleven quarters, ending latest Q4/2016. Each patient's individual study period was determined by the index date.

For the analysis of the adjusted study population collecting patients without cystectomy, the FU was shortened to three quarters ending latest Q4/2016. The main focus was on the first FU quarters to detect possible direct cost effects after the initial TURB. The pre-index period remained unchanged, resulting in an extended selection period of four years between Q2/2012 and Q1/2016, thus increasing the corresponding study population.

\section{Treatments}

The study population was divided into two cohorts depending on whether they underwent initial WL- or initial BLTURB. The cohorts were further divided depending on cystectomy for subgroup analysis and for the adjusted study population without cystectomy in InQ and FU.

\section{Statistics}

Descriptive analyses were applied for evaluation, using the $\chi^{2}$ test for categorical variables and the Wilcoxon rank-sum test for continuous variables. Differences were considered statistically significant if $p$ values were $<0.05$.

\section{Results}

\section{Characteristics of the study population}

The total study population comprised 2331 patients, 1855 (79.6\%) in the WL-cohort and $476(20.4 \%)$ in the BLcohort; significantly more patients received initial WL- than BL-TURB in the total study population as well as in both male and female subgroups. Likewise, in all persons continuously insured between 2011 and $2016(n=3,038,323)$ the incidence rate of initial WL-TURB according to cohort selection $(0.06 \%)$ was significantly higher than of BL-TURB $(0.02 \% ; p<0.001)$.

The demographic data of the study population are summarized in Table 1. Mean age and gender ratio were comparable between both cohorts, with more than three quarters of patients being men. More than $98 \%$ of patients had non-metastatic disease at the time of diagnosis in the InQ (Table 1). 


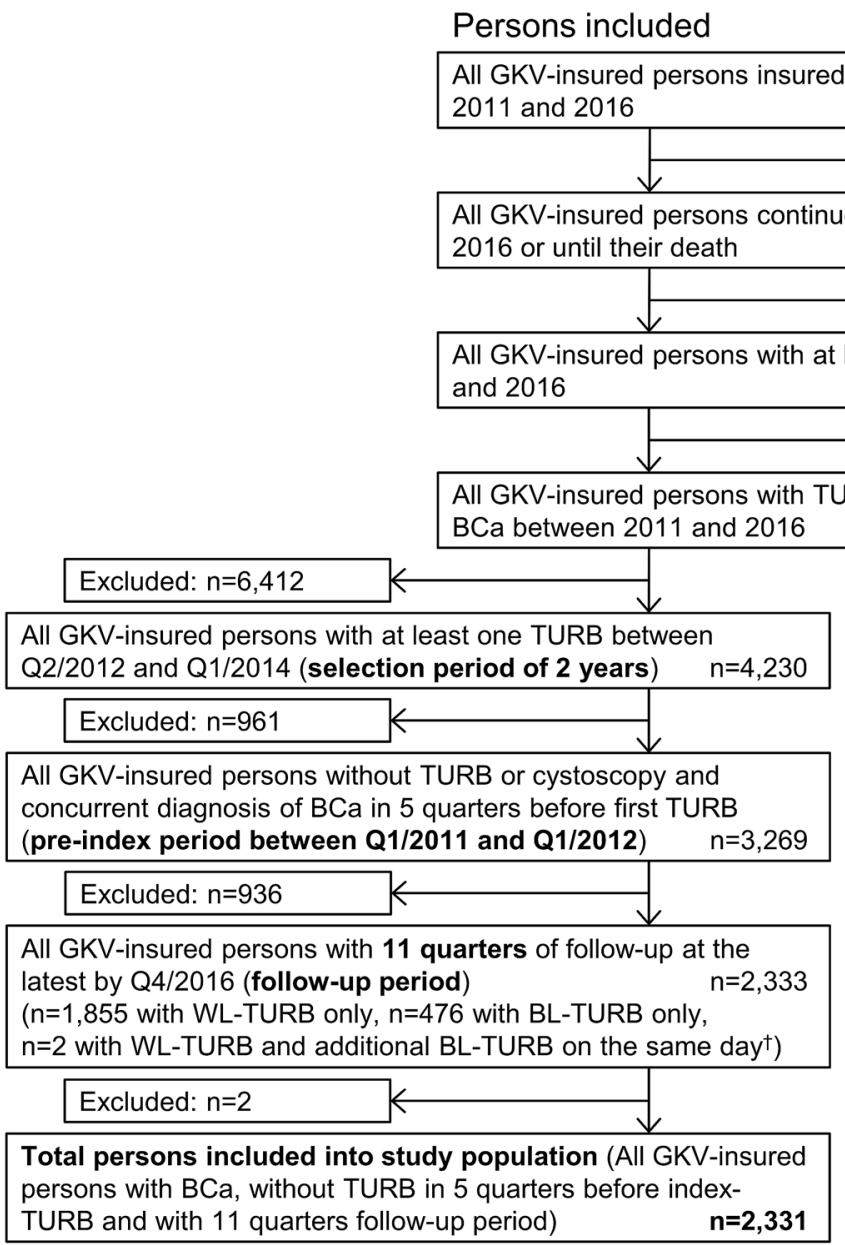

Fig. 1 Selection of study population (left) and adjusted study population (right). Inclusion criteria were applied stepwise. Diagnosis of bladder cancer (BCa) was based on International Classification of Diseases, 10th Revision, German Modification (ICD-10-GM): C67, malignant neoplasm of bladder or D09.0, carcinoma in situ of the bladder; inpatient or outpatient confirmed. TURB, cystoscopy and

\section{Cost analysis of the study population}

Costs $^{1}$ were calculated from the perspective of a statutory health insurance (Table 2A). In the InQ, the mean total costs of EUR 5687 in the BL-cohort were significantly higher than the mean total costs of EUR 4609 in the WL-cohort $(p<0.001)$, resulting from both higher inpatient and medicinal product costs in the BL-cohort. However, in the FU, mean total costs were not significantly different between

\footnotetext{
$\overline{1}$ Total costs considered the following cost domains: outpatient, inpatient, medicinal products, appliances, remedies, and sick pay.
}

cystectomy were based on German Operations and Procedures Key (OPS Code): 5-573.40 (WL-TURB), 5-573.41/5-573.4x (BL-TURB), inpatient (OPS code 5-573.2 for transurethral excision was not included); 1-661/1-663/1-693.2 (cystoscopy), inpatient or outpatient; 5-575 (partial cystectomy), 5-576 (simple/radical cystectomy), inpatient. ${ }^{\dagger} n<5$ excluded ensuring statistical anonymity.

both cohorts (WL: EUR 20,442; BL: 20,253; $p=0.794$ ). Altogether, total costs over time were EUR 25,940 in the BL-cohort and hence not significantly higher than in the WL-cohort (EUR 25,051; $p=0.525$ ).

\section{Subgroup analysis of costs: cystectomy}

To investigate the impact of cystectomy in the total study population, a subgroup with cystectomy $(n=351)$ was compared to a subgroup without cystectomy in InQ and FU $(n=1980)$. Cystectomy rates were not significantly different between both cohorts (WL: 15.3\%, BL: $14.1 \%$; $p=0.502$ ). Regarding total costs over time, subgroup analysis showed 
Table 1 Demographic data and disease states of bladder cancer of the total study population and per cohort in the index quarter

\begin{tabular}{|c|c|c|c|c|}
\hline \multirow[t]{2}{*}{ Characteristics } & \multicolumn{4}{|l|}{ Study population } \\
\hline & Total $(N=2331)$ & $\begin{array}{l}\text { WL-TURB cohort } \\
(N=1855)\end{array}$ & $\begin{array}{l}\text { BL-TURB cohort } \\
(N=476)\end{array}$ & $p^{\dagger}$ \\
\hline \multicolumn{5}{|l|}{ Sex } \\
\hline Male $(\%)$ & 79.45 & 79.78 & 78.15 & 0.431 \\
\hline Female (\%) & 20.55 & 20.22 & 21.85 & \\
\hline \multicolumn{5}{|l|}{ Age (years) } \\
\hline Mean \pm SD & $69.16 \pm 10.88$ & $69.48 \pm 10.86$ & $67.90 \pm 10.86$ & 0.663 \\
\hline Median & 71 & 71 & 69 & \\
\hline \multicolumn{5}{|l|}{ Age group (\%) } \\
\hline $0-39$ & 0.90 & 0.97 & 0.63 & \\
\hline $40-49$ & 4.63 & 4.20 & 6.30 & \\
\hline $50-59$ & 13.47 & 13.32 & 14.08 & \\
\hline $60-69$ & 25.48 & 24.53 & 29.20 & \\
\hline $70-79$ & 38.61 & 39.46 & 35.29 & \\
\hline $80-89$ & 16.39 & 17.04 & 13.87 & \\
\hline $90+$ & 0.51 & 0.49 & 0.63 & \\
\hline \multicolumn{5}{|c|}{$\begin{array}{l}\text { Stage of bladder cancer } \\
\text { according to Coding }{ }^{\ddagger}(\%)\end{array}$} \\
\hline N0 and M0 & 98.93 & 98.98 & 98.74 & 0.655 \\
\hline N1 and M0 & 0.86 & 0.81 & 1.05 & 0.610 \\
\hline N0 and M1 & 0.21 & 0.22 & 0.21 & 0.981 \\
\hline $\mathrm{N} 1$ and M1 & 0.00 & 0.00 & 0.00 & - \\
\hline
\end{tabular}

${ }^{\dagger}$ WL- vs. BL-cohort. ${ }^{\ddagger}$ The findings are based on the International Classification of Diseases, 10th Revision, German Modification (ICD-10-GM) and do not result from clinical histopathological TNM staging. No lymph node metastases (=N0); no distant metastases $(=\mathrm{M} 0)$; lymph node metastases $(=\mathrm{N} 1)$; distant metastases $(=\mathrm{M} 1)$ that expenses were more than twice as high for patients with cystectomy as for patients without cystectomy (Table 2B). In the cystectomy subgroup, mean total costs were significantly higher in the InQ, resulting from higher inpatient and medicinal product costs. During FU, costs remained on a high, but not significantly different level in both BL- and WL-cohorts. In the subgroup without cystectomy, the mean total costs were considerably lower and similar between the WL- and the BL-cohort in both InQ and FU.

\section{Cost analysis of the adjusted study population}

As cystectomy was identified as an important cost driver contributing greatly to the total costs in both cohorts, an additional cost analysis was performed for an adjusted study population only including patients without cystectomy in InQ and FU. To evaluate any possible direct effects of the first TURB, only the first three quarters of follow-up were included in the analysis. This shortening of the FU resulted in an increased selection period from two to four years yielding a higher number of patients included.

The adjusted study population comprised 4541 patients, with $3582(78.9 \%)$ in the WL- and 959 (21.1\%) in the BLcohort. In accordance with the first results of the subgroup analyses without cystectomy (Table 2B), mean total costs in the InQ were comparable in both cohorts (BL: EU 4543 vs WL: EUR 4534). Over the entire three FU quarters, the mean total costs of EUR 6431 in the BL-cohort were significantly lower $(p=0.045)$ than the mean total costs of EUR 7073 in the WL-cohort (Fig. 2).

Regarding median values, total costs in the InQ were slightly higher in the BL-cohort (EUR 3704 vs EUR 3320). However, over the FU period, also the median total costs of EUR 4426 in the BL-cohort were below the total of the WL-cohort (EUR 4655), thereby "compensating" the higher median initial costs in the BL-cohort.

Considering the individual quarters, the mean total costs in each FU quarter were clearly lower as in the InQ in both cohorts. In each FU quarter, the quarterly costs tended to be lower in the BL- than in the WL-cohort; those differences were most prominent in the second FU quarter but decreased in the third FU quarter. After one year a comparable cost level was reached (Fig. 2). 
Table 2 Cost tables for study population

2A: Total costs and main cost domains per cohort in index quarter and follow-up period

\begin{tabular}{|c|c|c|c|c|c|c|c|c|c|}
\hline \multirow[b]{2}{*}{ Cohort } & \multicolumn{3}{|c|}{$\begin{array}{l}\text { Total (index quarter }+11 \text { quarters follow- } \\
\text { up) }\end{array}$} & \multicolumn{3}{|l|}{ Index quarter } & \multicolumn{3}{|c|}{ Follow-up period (11 quarters) } \\
\hline & WL & BL & $p$ & WL & $\mathrm{BL}$ & $p$ & WL & $\mathrm{BL}$ & $p$ \\
\hline \multicolumn{10}{|c|}{ Study population } \\
\hline$N$ & 1,855 & 476 & & & & & & & \\
\hline \multicolumn{10}{|c|}{ Total costs ${ }^{\dagger}(€)$} \\
\hline Mean \pm SD & $25,051 \pm 21,607$ & $25,940 \pm 42,550$ & 0.525 & $4609 \pm 3974$ & $5687 \pm 14,505$ & $<0.001$ & $20,442 \pm 20,480$ & $20,253 \pm 31,017$ & 0.794 \\
\hline Median & 18,904 & 17,803 & & 3174 & 3552 & & 14,261 & 13,510 & \\
\hline \multicolumn{10}{|c|}{ Cost domains $(€)$} \\
\hline \multicolumn{10}{|c|}{ Outpatient treatment } \\
\hline Mean \pm SD & $3977 \pm 2754$ & $3875 \pm 2110$ & 0.772 & $402 \pm 355$ & $379 \pm 270$ & 0.174 & $3574 \pm 2648$ & $3497 \pm 1979$ & 0.549 \\
\hline Median & 3397 & 3419 & & 298 & 309 & & 3032 & 3065 & \\
\hline \multicolumn{10}{|c|}{ Inpatient treatment } \\
\hline Mean \pm SD & $15,261 \pm 16,054$ & $14,261 \pm 14,117$ & 0.215 & $3857 \pm 3821$ & $4309 \pm 4388$ & $<0.001$ & $11,405 \pm 15,203$ & $9,953 \pm 13,092$ & 0.056 \\
\hline Median & 10,262 & 9419 & & 2322 & 2811 & & 6726 & 5329 & \\
\hline \multicolumn{10}{|c|}{ Medicinal products } \\
\hline Mean \pm SD & $3823 \pm 7997$ & $5847 \pm 35,455$ & 0.025 & $286 \pm 619$ & $949 \pm 12,946$ & $<0.001$ & $3537 \pm 7573$ & $4897 \pm 23,822$ & 0.037 \\
\hline Median & 2295 & 2304 & & 110 & 109 & & 2022 & 2074 & \\
\hline
\end{tabular}

2B: Total costs per cohort in index quarter and follow-up period for subgroups with and without cystectomy

\begin{tabular}{|c|c|c|c|c|c|c|c|c|c|}
\hline \multirow[b]{2}{*}{ Cohort } & \multicolumn{3}{|c|}{$\begin{array}{l}\text { Total (index quarter }+11 \text { quarters follow- } \\
\text { up) }\end{array}$} & \multicolumn{3}{|l|}{ Index quarter } & \multicolumn{3}{|c|}{ Follow-up period (11 quarters) } \\
\hline & WL & BL & $p$ & WL & $\mathrm{BL}$ & $p$ & WL & $\mathrm{BL}$ & $p$ \\
\hline \multicolumn{10}{|c|}{ SUBGROUP WITH CYSTECTOMY ${ }^{\dagger \dagger}$} \\
\hline$N$ & 284 & 67 & & & & & & & \\
\hline \multicolumn{10}{|l|}{ Total costs $(€)$} \\
\hline Mean \pm SD & $45,947 \pm 26,076$ & $58,278 \pm 94,333$ & 0.056 & $7753 \pm 6662$ & $14,412 \pm 37,038$ & 0.005 & $38,194 \pm 26,729$ & $43,866 \pm 60,580$ & 0.719 \\
\hline Median & 38,232 & 42,513 & & 4659 & 5262 & & 31,744 & 33,491 & \\
\hline \multicolumn{10}{|c|}{ SUBGROUP WITHOUT CYSTECTOMY ${ }^{\dagger \dagger}$} \\
\hline$N$ & 1,571 & 409 & & & & & & & \\
\hline \multicolumn{10}{|l|}{ Total costs $(€)$} \\
\hline Mean \pm SD & $21,273 \pm 18,317$ & $20,642 \pm 21,645$ & 0.551 & $4040 \pm 2922$ & $4258 \pm 2912$ & 0.179 & $17,233 \pm 17,298$ & $16,384 \pm 20,489$ & 0.396 \\
\hline Median & 16,221 & 15,922 & & 3074 & 3398 & & 12,433 & 12,016 & \\
\hline
\end{tabular}

${ }^{\dagger}$ Beside the main cost domains outpatient, inpatient, and medicinal products, the cost domains appliances, remedies, and sick pay were also included in total costs but are not shown individually

${ }^{\dagger \dagger}$ Cystectomy was based on German Operations and Procedures Key (OPS Code): 5-575 (partial cystectomy), inpatient; 5-576 (simple/radical cystectomy), inpatient

\section{Subsequent cystoscopies/TURB of the adjusted study population}

After the initial TURB, most patients of the BL-cohort and the WL-cohort were subsequently examined by at least one cystoscopy in InQ and FU. Regarding TURB, in total a higher proportion of patients was subsequently examined by WL-TURB than by BL-TURB in both cohorts. The rate of subsequent WL-TURB was significantly higher in the WL-cohort than in the BL-cohort. A significantly higher proportion of the BL-cohort than of the WL-cohort subsequently received further BL-TURB (data not shown).

\section{Discussion}

This comparative retrospective analysis of real-world data on prevailing TURB treatments of BCa showed that in Germany only $20 \%$ of GKV-insured persons with $\mathrm{BCa}$ receive initial BL-TURB, despite its therapeutic benefits compared 


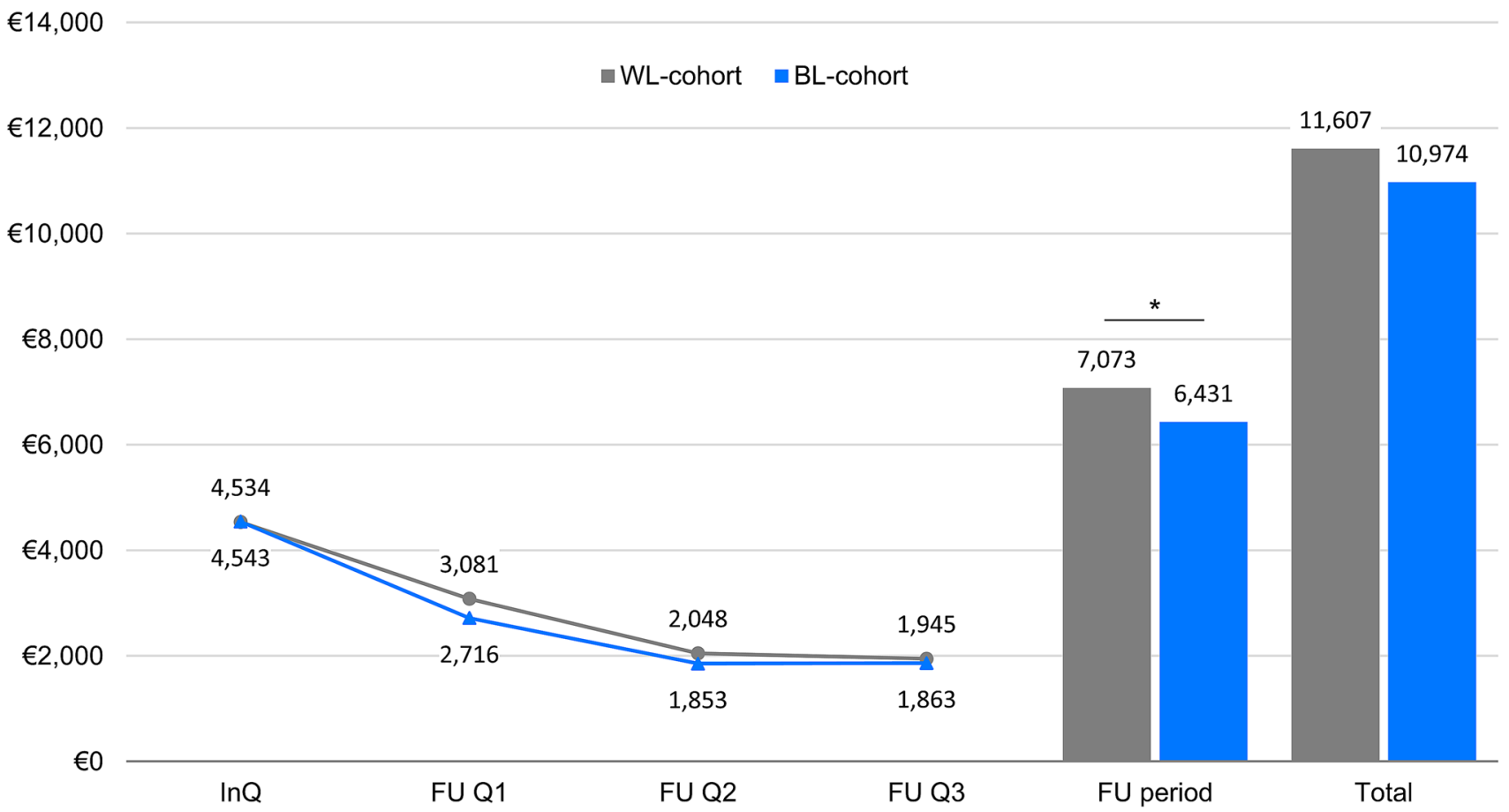

Fig. 2 Total costs and development of costs per cohort in the index quarter and follow-up period (adjusted study population). Data are given as mean. WL- vs. BL-cohort * $p<0.05$. FU, follow-up period ( 3 quarters); InQ, index quarter; Total (index quarter +3 quarters follow-up)

to WL-TURB and its recommendation in guidelines $[3,25]$. Availability of equipment and acquisition costs as well as additional costs of HAL may restrict the use of BL-TURB in clinical practice. Furthermore, a bias due to incorrect coding of surgical procedures with a possible impact on the unbalanced distribution ratio cannot be excluded.

In this study, initial BL-TURB resulted only in the primary study population in higher initial costs compared to WL-TURB. Subgroup analysis identified cystectomy as a main contributor to costs, masking potential directly TURBmediated differences. When cystectomy was excluded for further analyses in an adjusted study population, the initial mean total costs of BL-TURB were comparable to WLTURB, and in the FU, costs of BL-TURB even tended to be lower compared to WL-TURB until they equalized after one year. The view on the median costs supports the trend of the superiority of BL-TURB compared to WL-TURB regarding total costs in the first year: Albeit the initial median costs of the BL-cohort tended to be higher, they were compensated by the lower mean FU costs. The findings of this study are in line with previous results of models for the cost-utility analysis of BL-TURB. Here, higher or similar initial costs of BL-TURB compared to WL-TURB are predicted which are compensated by cost benefits in the long term due to improved patient outcomes [20-23]. In a Markov model calculated for Germany, additional initial BL-TURB reduced costs by EUR 537 per patient compared to only WL-TURB.
At the same time, quality-adjusted life years were increased [22]. Witjes et al. [20] suggest that previous restrictions of BL-TURB due to budget need to be adjusted to recent longterm follow-up data and cost analyses.

The study specifically focused on real-world BCa-treatment costs of initial WL- versus BL-TURB in Germany based on claims data, whose original function is reimbursement of healthcare costs. Therefore, the study results were dependent on the quality of coding and classification and apply for German statutory health insurances only. Outcomes irrelevant for reimbursement may be precluded, resulting in under-representation or inadequately documentation of clinical factors like metastases.

The analyzed claims data do not allow the confirmation of the medical hypothesis that BL-TURB is associated with a higher risk reduction of recurrence than WL-TURB. The design of this study involved a pre-index period without TURB or cystectomy and concurrent diagnosis of $\mathrm{BCa}$ to ensure that only patients with their initial TURB in the selection period were included. However, this approach does not exclude subsequent TURB completely. Furthermore, low and varying numbers of patients in the subgroup analysis may impact the respective results. Unfortunately, the retrospective study feature does not allow to evaluate the assignment reason to the two procedures $\mathrm{WL}$ or $\mathrm{BL}$ which is one aspect of the main limitation of this healthcare study: the lack of clinical parameters. 


\section{Conclusion}

This comparative retrospective analysis of healthcare claims data provides information on real-world costs of standard WL- or HAL-guided BL-TURB for treatment of BCa in Germany. The application of a BL-TURB does not imply higher initial and consecutive costs than the WL-TURB. In combination with a higher tumor detection rate and consequently lower recurrence risk, described in a variety of clinical trials and publications, BL-TURB constitutes a valuable addition to standard WL-TURB. Nonetheless, initial BL-TURB was still only performed in every fifth GKV-insured patient with BCa. However, limitations of the analysis of healthcare claims data need to be considered, when interpreting the study results.

Acknowledgements The authors thank Dr. Christiane Ring at co.medical (Berlin, Germany) for providing medical writing support, which was sponsored by Ipsen Pharma GmbH (Munich, Germany) in accordance with Good Publication Practice guidelines.

Author contributions TT, BQ and AS: project development, manuscript editing. MM: manuscript editing. MK, NK: data collection, management and analysis. CC: project development, manuscript writing and editing.

Funding Open Access funding enabled and organized by Projekt DEAL. This work was supported by Ipsen Pharma GmbH, Munich, Germany.

\section{Compliance with ethical standards}

Conflict of interest Tilman Todenhöfer: speaker/advisor for Amgen, Astellas, AstraZeneca, Bayer, BMS, Ipsen, Janssen, MSD, Roche. Moritz Maas: none. Miriam Ketz: none. Nils Kossack: none. Christiane Colling: former employee of Ipsen Pharma. Bryan Qvick: employee of Ipsen Pharma. Arnulf Stenzl: speaker/advisor for Alere, Amgen, Astellas, Bristol Myers Squibb, CureVac, Ferring, Ipsen, Janssen, Roche, Sanofi Aventis, Stebabiotech, Synergo.

Informed consent This work is based on routine healthcare claims data. As anonymized and pseudonymized healthcare claims data were evaluated, the study was exempt from ethical approval, no informed consent was required.

Research involving human participants and/or animals This work did not include animal studies. Data concerning human patients were collected retrospectively.

Open Access This article is licensed under a Creative Commons Attribution 4.0 International License, which permits use, sharing, adaptation, distribution and reproduction in any medium or format, as long as you give appropriate credit to the original author(s) and the source, provide a link to the Creative Commons licence, and indicate if changes were made. The images or other third party material in this article are included in the article's Creative Commons licence, unless indicated otherwise in a credit line to the material. If material is not included in the article's Creative Commons licence and your intended use is not permitted by statutory regulation or exceeds the permitted use, you will need to obtain permission directly from the copyright holder. To view a copy of this licence, visit http://creativecommons.org/licenses/by/4.0/.

\section{References}

1. International Agency for Research on Cancer. World Cancer Report 2014 (2014) http://publications.iarc.fr/Non-Series-Publi cations/World-Cancer-Reports/World-Cancer-Report-2014. Accessed 14 May 2019

2. Leal J, Luengo-Fernandez R, Sullivan R, Witjes JA (2016) Economic burden of bladder cancer across the European union. Eur Urol 69(3):438-447. https://doi.org/10.1016/j.eururo.2015.10.024

3. Leitlinienprogramm Onkologie (AWMF, DKG, DKH) (2016) S3-Leitlinie Früherkennung, Diagnose, Therapie und Nachsorge des Harnblasenkarzinoms, Langversion1.1, 2016, AWMF-Registrierungsnummer 032/0380. http://leitlinienprogramm-onkologie. de/Harnblasenkarzinom.92.0.html. Accessed 3 May 2019

4. Zentrum für Krebsregisterdaten im Robert Koch-Institut. Bericht zum Krebsgeschehen in Deutschland 2016 (2016) https://www. krebsdaten.de/Krebs/DE/Content/Publikationen/Krebsgesch ehen/Krebsgeschehen_download.pdf?__blob=publicationFile. Accessed 14 May 2019

5. Bach T, Muschter R, Herrmann TR, Knoll T, Scoffone CM, Laguna MP, Skolarikos A, Rischmann P, Janetschek G, De la Rosette JJ, Nagele U, Malavaud B, Breda A, Palou J, Bachmann A, Frede T, Geavlete P, Liatsikos E, Jichlinski P, Schwaibold HE, Chlosta P, Martov AG, Lapini A, Schmidbauer J, Djavan B, Stenzl A, Brausi M, Rassweiler JJ (2015) Technical solutions to improve the management of non-muscle-invasive transitional cell carcinoma: summary of a European Association of Urology Section for Uro-Technology (ESUT) and Section for Uro-Oncology (ESOU) expert meeting and current and future perspectives. BJU Int 115(1):14-23. https://doi.org/10.1111/bju.12664

6. Babjuk M, Böhle A, Burger M, Capoun O, Cohen D, Compérat EM, Hernández V, Kaasinen E, Palou J, Rouprêt M, van Rhijn BW, Shariat SF, Soukup V, Sylvester RJ, Zigeuner R (2017) EAU guidelines on non-muscle-invasive urothelial carcinoma of the bladder: update 2016. Eur Urol 71(3):447-461. https://doi. org/10.1016/j.eururo.2016.05.041

7. Frampton JE, Plosker GL (2006) Hexyl aminolevulinate: in the detection of bladder cancer. Drugs 66(4):571-578 https://doi. org/10.2165/00003495-200666040-00010 (discussion 579-580)

8. Daneshmand S, Bazargani ST, Bivalacqua TJ, Holzbeierlein JM, Willard B, Taylor JM, Liao JC, Pohar K, Tierney J, Konety B (2018) Blue light cystoscopy for the diagnosis of bladder cancer: results from the US prospective multicenter registry. Urol Oncol 36(8):361.e361-361.e366. https://doi.org/10.1016/j.urolo nc.2018.04.013

9. Jocham D, Witjes F, Wagner S, Zeylemaker B, van Moorselaar J, Grimm MO, Muschter R, Popken G, König F, Knüchel R, Kurth $\mathrm{KH}$ (2005) Improved detection and treatment of bladder cancer using hexaminolevulinate imaging: a prospective, phase III multicenter study. J Urol 174(3):862-866. https://doi.org/10.1097/01. ju.0000169257.19841.2a (discussion 866)

10. Burger M, Grossman HB, Droller M, Schmidbauer J, Hermann G, Drăgoescu O, Ray E, Fradet Y, Karl A, Burgués JP, Witjes JA, Stenzl A, Jichlinski P, Jocham D (2013) Photodynamic diagnosis of non-muscle-invasive bladder cancer with hexaminolevulinate cystoscopy: a meta-analysis of detection and recurrence based on raw data. Eur Urol 64(5):846-854. https://doi.org/10.1016/j.eurur o.2013.03.059

11. Daneshmand S, Patel S, Lotan Y, Pohar K, Trabulsi E, Woods M, Downs T, Huang W, Jones J, O'Donnell M, Bivalacqua T, DeCastro J, Steinberg G, Kamat A, Resnick M, Konety B, Schoenberg M, Jones JS (2018) Efficacy and safety of blue light flexible cystoscopy with hexaminolevulinate in the surveillance of bladder cancer: a phase III, comparative, multicenter study. J Urol 199(5):1158-1165. https://doi.org/10.1016/j.juro.2017.11.096 
12. Geavlete B, Multescu R, Georgescu D, Jecu M, Stanescu F, Geavlete $P$ (2012) Treatment changes and long-term recurrence rates after hexaminolevulinate (HAL) fluorescence cystoscopy: does it really make a difference in patients with non-muscle-invasive bladder cancer (NMIBC)? BJU Int 109(4):549-556. https://doi. org/10.1111/j.1464-410X.2011.10374.x

13. Gallagher KM, Gray K, Anderson CH, Lee H, Stewart S, Donat R, Mariappan P (2017) "Real-life experience": recurrence rate at 3 years with Hexvix( $\left({ }^{\circledR}\right)$ photodynamic diagnosis-assisted TURBT compared with good quality white light TURBT in new NMIBCa prospective controlled study. World J Urol 35(12):1871-1877. https://doi.org/10.1007/s00345-017-2077-6

14. Stenzl A, Burger M, Fradet Y, Mynderse LA, Soloway MS, Witjes JA, Kriegmair M, Karl A, Shen Y, Grossman HB (2010) Hexaminolevulinate guided fluorescence cystoscopy reduces recurrence in patients with nonmuscle invasive bladder cancer. J Urol 184(5):1907-1913. https://doi.org/10.1016/j.juro.2010.06.148

15. Grossman HB, Stenzl A, Fradet Y, Mynderse LA, Kriegmair M, Witjes JA, Soloway MS, Karl A, Burger M (2012) Long-term decrease in bladder cancer recurrence with hexaminolevulinate enabled fluorescence cystoscopy. J Urol 188(1):58-62. https://doi. org/10.1016/j.juro.2012.03.007

16. Rink M, Babjuk M, Catto JW, Jichlinski P, Shariat SF, Stenzl A, Stepp H, Zaak D, Witjes JA (2013) Hexyl aminolevulinateguided fluorescence cystoscopy in the diagnosis and follow-up of patients with non-muscle-invasive bladder cancer: a critical review of the current literature. Eur Urol 64(4):624-638. https:// doi.org/10.1016/j.eururo.2013.07.007

17. Gakis G, Fahmy O (2016) Systematic review and meta-analysis on the impact of hexaminolevulinate- versus white-light guided transurethral bladder tumor resection on progression in non-muscle invasive bladder cancer. Bladder Cancer 2(3):293-300. https:// doi.org/10.3233/blc-160060

18. Kamat AM, Cookson M, Witjes JA, Stenzl A, Grossman HB (2016) The impact of blue light cystoscopy with hexaminolevulinate (HAL) on progression of bladder cancer-a new analysis. Bladder Cancer 2(2):273-278. https://doi.org/10.3233/blc-160048

19. Renninger M, Fahmy O, Schubert T, Schmid MA, Hassan F, Stenzl A, Gakis G (2020) The prognostic impact of hexaminolevulinate-based bladder tumor resection in patients with primary non-muscle invasive bladder cancer treated with radical cystectomy. World J Urol 38(2):397-406. https://doi.org/10.1007/ s00345-019-02780-0

20. Witjes JA, Babjuk M, Gontero P, Jacqmin D, Karl A, Kruck S, Mariappan P, Palou Redorta J, Stenzl A, van Velthoven R, Zaak D (2014) Clinical and cost effectiveness of hexaminolevulinateguided blue-light cystoscopy: evidence review and updated expert recommendations. Eur Urol 66(5):863-871. https://doi. org/10.1016/j.eururo.2014.06.037

21. Sievert KD, Amend B, Nagele U, Schilling D, Bedke J, Horstmann M, Hennenlotter J, Kruck S, Stenzl A (2009) Economic aspects of bladder cancer: what are the benefits and costs? World J Urol 27(3):295-300. https://doi.org/10.1007/s00345-009-0395-Z

22. Gakis G, Volkmer B, Qvick B, Marteau F, Stenzl A (2019) Costeffectiveness analysis of blue light cystoscopy with hexylaminolevulinate in transurethral resection of the bladder. Der Urologe Ausg A 58(1):34-40. https://doi.org/10.1007/s00120-018-0624-4

23. Rouprêt M, Malavaud B, Molinier L, Leleu H, Blachier M, Marteau F (2015) Cost-effectiveness of transurethral resection of the bladder with blue light in patients with non muscle invasive bladder cancer in France. Prog Urol 25(5):256-264. https://doi. org/10.1016/j.purol.2015.01.004

24. Andersohn F, Walker J (2016) Characteristics and external validity of the German health risk institute (HRI) database. Pharmacoepidemiol Drug Saf 25(1):106-109. https://doi.org/10.1002/pds.3895

25. Rouprêt M, Neuzillet Y, Masson-Lecomte A, Colin P, Compérat E, Dubosq F, Houédé N, Larré S, Pignot G, Puech P, Roumiguié M, Xylinas E, Méjean A (2016) CCAFU french national guidelines 2016-2018 on bladder cancer. Prog Urol 27(Suppl 1):S67s91. https://doi.org/10.1016/s1166-7087(16)30704-7

Publisher's Note Springer Nature remains neutral with regard to jurisdictional claims in published maps and institutional affiliations.

\section{Authors and Affiliations}

\section{Tilman Todenhöfer ${ }^{1,2}$ (]) $\cdot$ Moritz Maas ${ }^{1} \cdot$ Miriam Ketz $^{3} \cdot$ Nils Kossack $^{4} \cdot$ Christiane Colling $^{5} \cdot$ Bryan $_{\text {Qvick }}$. Arnulf Stenzl ${ }^{1}$}

\author{
Moritz Maas \\ moritz.maas@med.uni-tuebingen.de \\ Miriam Ketz \\ ketz@dtod.de \\ Nils Kossack \\ nils.kossack@wig2.de \\ Christiane Colling \\ co@dr-hoffmanns.de \\ Bryan Qvick \\ bryan.qvick@ipsen.com \\ Arnulf Stenzl \\ Arnulf.Stenzl@med.uni-tuebingen.de
}

1 Department of Urology, University of Tuebingen, Hoppe-Seyler-Straße 3, 72076 Tübingen, Germany

2 Studienpraxis Urologie, Steinengrabenstr. 17, 72622 Nürtingen, Germany

3 DtoD - Data to Decision - AG, Heimhuder Straße 52, 20148 Hamburg, Germany

4 WIG2 GmbH, Scientific Institute for Health Economics and Health System Research, Markt 8, 04109 Leipzig, Germany

5 Ipsen Pharma GmbH, Einsteinstr. 174, 81677 Munich, Germany 